\title{
Upper cervical spinal bronchogenic cyst: A rare lesion at an exceptional location
}

\author{
Viral Patel, Shreya Desai, Vishal Thakkar, Sanjay Chaudhari1 \\ Departments of Radio-Diagnosis and 'Pathology, Pramukh Swami Medical College and Shree Krishna Hospital, \\ Karamsad, Gujarat, India
}

Correspondence: Dr. Shreya Desai, Department of Radio-Diagnosis, Shree Krishna Hospital and Pramukhswami Medical College, Karamsad 388 325, Gujarat, India. E-mail: drshreya.p.desai@gmail.com; shreyapd@charutarhealth.org

\section{Abstract}

An intraspinal bronchogenic cyst is a rare but important cause of compressive cord myelopathy, commonly seen in the cervicothoracic spine. We report a case of a 30-year-old female, presented with complaints of neck pain and progressive weakness of the extremities. The magnetic resonance imaging of the cervical spine revealed an intradural extramedullary, well-defined, multiloculated, cystic lesion in the upper cervical canal extending from the C2 to C5 vertebral levels. To our knowledge, only 11 cases of spinal bronchogenic cysts have been reported in the literature so far. We discuss the rare location of this unusual lesion, possible embryological reasons, and the overall surgical outcome.

Key words: Compressive myelopathy; extramedullary; intradural; Spinal bronchogenic cyst; upper cervical

\section{Introduction}

Bronchogenic cysts are benign, congenital cystic lesions, and their location in the spine is extremely rare. ${ }^{[1]}$ Bronchogenic cyst, is a rare cause of space-occupying lesion in the spinal canal, accounting for approximately $0.5 \%$ of cases of cystic intraspinal lesions. ${ }^{[2]}$ They arise as developmental abnormalities of the embryonic foregut. Hence, bronchogenic cysts are commonly seen in the posterior mediastinum, atypical locations include the pericardium, sternum, skin, and spinal cord..$^{[3]}$

The most common location of a bronchogenic cyst in the spine is the lower cervical and upper thoracic segments and almost all the cysts have an intradural and extramedullary location. ${ }^{[4]}$ The lesions enlarge slowly and cause compression

\begin{tabular}{|l|l|}
\hline \multicolumn{2}{|c|}{ Access this article online } \\
\hline Quick Response Code: & \\
\hline & Website: \\
\hline & www.ijri.org \\
\cline { 2 - 3 } & DOI: \\
\hline
\end{tabular}

of the spinal nerve root, anterior spinal artery and/or the spinal cord leading to symptoms of compressive myelopathy. ${ }^{[5]}$ None of the complications secondary to ruptured cysts have been reported, such as chemical meningitis, abscess formation, and hydrocephalus. It is difficult to make the correct diagnosis before surgery due to rarity and nontypical signs, symptoms of presentation and equivocal imaging findings. Histological examination of the cyst is necessary for the confirmation of the diagnosis. A lining of pseudostratified ciliated columnar epithelium resembling respiratory epithelium is the diagnostic hallmark of a spinal bronchogenic cyst (SBC). Rarely, malignant transformation of these cysts has been described

This is an open access journal, and articles are distributed under the terms of the Creative Commons Attribution-NonCommercial-ShareAlike 4.0 License, which allows others to remix, tweak, and build upon the work non-commercially, as long as appropriate credit is given and the new creations are licensed under the identical terms.

For reprints contact: WKHLRPMedknow_reprints@wolterskluwer.com

Cite this article as: Patel V, Desai S, Thakkar V, Chaudhari S. Upper cervical spinal bronchogenic cyst: A rare lesion at an exceptional location. Indian J Radiol Imaging 2020;30:513-6.

Received: 18-Jun-2019 Accepted: $21-$ Sep-2020

Revised: 11-Aug-2020 Published: 13-Jan-2021 
in the mediastinum but not in the spine. ${ }^{[6]}$ To the best of our knowledge,only 11 cases of SBC have been reported..$^{[7]}$ Cystic lesions common in this location include cystic schwannoma, epidermoid cyst, dermoid cyst, metastatic lesion. However, in a young patient bronchogenic cyst should also be considered in the differential diagnosis.

\section{Case Report}

A 30-year-old female presented with complaints of insidious onset, gradually progressive neck pain and progressive weakness initially in the left upper limb followed by the involvement of the left lower limb and right upper limb associated with difficulty in holding objects, without any associated trauma or infection. On the central nervous system (CNS) examination, the patient was conscious with a Glass Glow Coma Score of 15/15 with a short neck. Power in the upper and lower limb was $4 / 5$ with brisk deep tendon reflexes. Hofmann positive and jaw jerks were normal. Magnetic resonance imaging (MRI) of the cervical spine with contrast and whole spine screening was performed which revealed a well-defined, multiloculated elongated, rim enhancing, oval-shaped, and fluid signal intensity dorsal cystic mass [Figures 1A, B and 2A, B], measuring about $4.0 \mathrm{~cm} \times 1.0 \mathrm{~cm} \times 1.5 \mathrm{~cm}$ extending from the $\mathrm{C} 2$ to $\mathrm{C} 5$ vertebral levels. The lesion was located in the intradural, extramedullary compartment without any communication with the skin and subcutaneous tissue [Figure 3]. Inferiorly, the lesion obliterated the thecal sac and displaced and compressed the spinal cord anteriorly. An altered signal was seen in the cord just proximal to the cystic lesion at the level of the $\mathrm{C} 1$ vertebra suggesting focal cord edema. The patient underwent a C2 to C4 laminectomy and excision of the extramedullary lesion. Postoperatively, the patient had complete relief of symptoms. Histopathological examination of the specimen showed cysts lined by respiratory epithelium with sub epithelial seromucinous glands, cartilage, smooth muscles, and fibro adipose tissue along with stromal inflammation, lymphoid aggregates, and congestion, suggestive of a bronchogenic cyst. The patient was completely asymptomatic at the time of follow-up.

\section{Discussion}

As per the WHO, a bronchogenic cyst is a type of entrogenous cyst which is lined by respiratory epithelium. ${ }^{[8]}$ Entrogenous cysts represent $0.7 \%-1.3 \%$ of total spinal cord tumors. ${ }^{[9]}$

The origin of a bronchogenic cyst is not completely known, but this pathological entity has been proposed to result from three hypotheses during embryogenesis. ${ }^{[3]}$ At first, it is assumed that the endoderm and ectoderm do not separate completely during differentiation of the inner cell mass. Secondly, the cyst is considered to originate from the ectoderm because of its potential to form endoderm
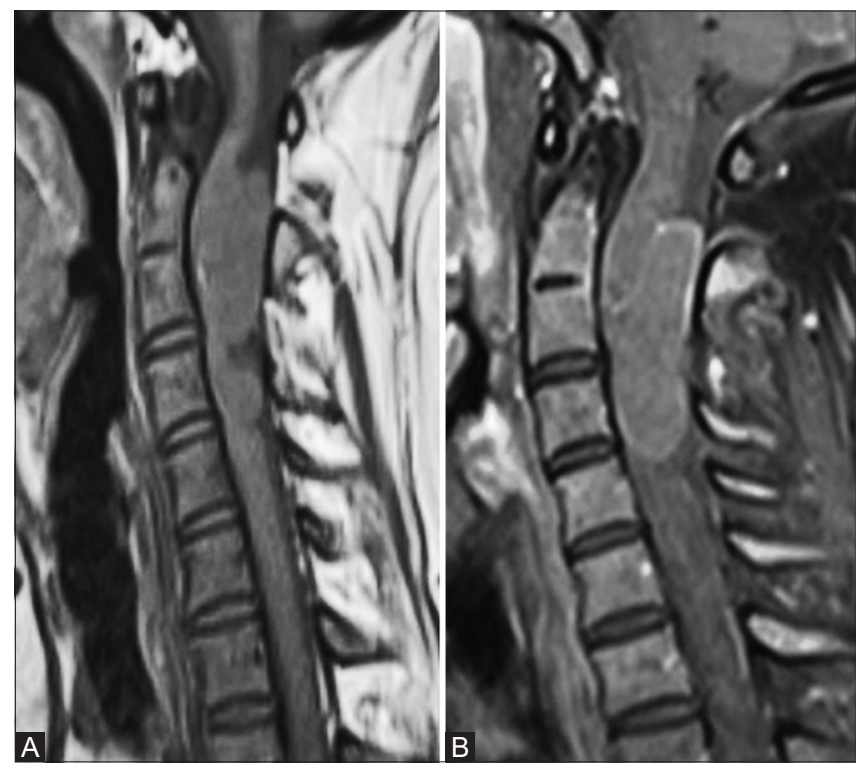

Figure 1 ( $A$ and $B)$ : $(A$ and $B$ ): T1w and T1w post contrast sagittal image showing fluid signal intensity dorsal cystic mass from the $\mathrm{C} 2$ to C5 vertebra

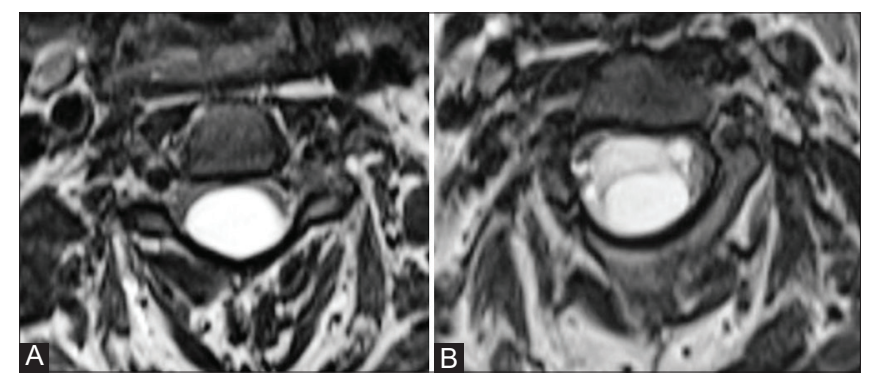

Figure 2 ( $A$ and $B$ ): (A and B ): T2w and STIR axial image showing fluid signal intensity dorsal cystic mass

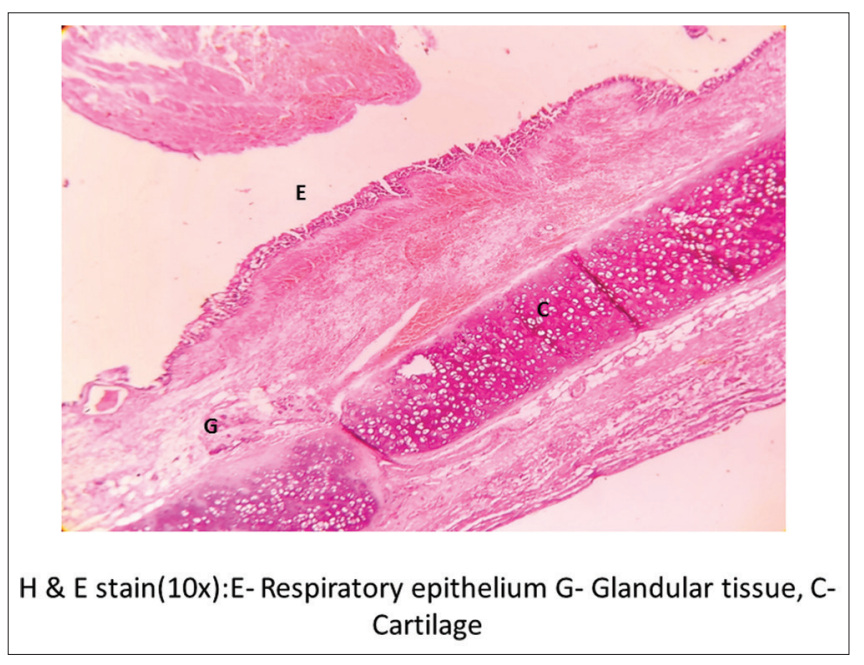

Figure 3: T2 coronal images show fluid signal intensity mass intradural extramedullary in location

and paraxial mesoderm. Lastly, it is attributed to the split notochord syndrome which can explain the ectopic bronchogenic cyst. When the duplication or separation of the notochord is incomplete, ectopic cysts are generated 
and present the characteristics of any part of the foregut. ${ }^{[10]}$ These cysts are, thus, expectedly seen in the cervicothoracic region and the thoracic spine as it is the cranial end of the notochord which develops first and is vulnerable to embryological anomalies at this time. Hence, SBC has been rarely reported above the C3 vertebral level. Not surprisingly, in our case, no vertebral anomalies such as hemivertebra, spina bifida, or fusion anomalies of the vertebra were noted in view of the rare upper cervical spine location of the cyst. This makes our case unique from an embryological perspective. Thus, our case report gives more reliance on the first and the second theory of SBC rather than the split notochord theory. ${ }^{[11]}$ Ectopic bronchogenic cysts located at the lumbar spine are more likely associated with spinal deformities such as spina bifida and tethering of the cord unlike the ones located at the cervical and thoracic level. ${ }^{[12]}$ Therefore, it is proposed that a common embryological anomaly causing both cord tethering and lumbar SBC. ${ }^{[13]}$ Thus, based on these studies, we can make a hypothesis that SBC may have a multicausal embryological origin which may be dependent on the location of the SBC in the spine.

Cystic lesions of the spine usually become symptomatic after secondary changes such as infection, rupture, increase in size, or after trauma to the spine. However, in the present case, there were no secondary changes in the cyst. Typically, SBCs are extremely slow growing due to the presence of tight junction in the epithelium and, thus, they may become symptomatic by a gradual increase in the size of the cyst by causing pressure symptoms on the surrounding neural structures. Wang et al. studied 21 adult patients with intradural spinal arachnoid cysts and suggested that ventral cysts presented more commonly with weakness and myelopathy, while dorsal cysts were more inclined to lead to neuropathic pain and numbness. ${ }^{[14]}$

As SBCs are rare and have no specific characteristics, the likelihood of diagnosis is delayed and often diagnosed by MRI. MRI is the diagnostic modality of choice to delineate the lesion from the overlying soft tissue and because of the relationship of the SBC to the cord. The most commonly seen characteristics on MRI is the presence of T1-hypointensity and T2-hyperintensity, without contrast enhancement. The following commonly seen cystic lesions are in the differential list which include: (i) Spinal arachnoid cysts, which are more commonly found in the dorsal part of the thoracic spinal canal and present with a CSF signal intensity on all MRI sequences. ${ }^{[14-19]}$ (ii) Spinal dermoid cysts and epidermoid cysts, which can be intramedullary, intradural extramedullary, or extradural and mostly occur at the lumbosacral region. MR images can present with different intensities due to various lipids in the cystic fluid (cholesterol crystals, lipid metabolites, and keratin). ${ }^{[20]}$ High signal on diffusion-weighed imaging (DWI) helps differentiate from other cystic diseases. ${ }^{[21]}$ iii) Spinal mature cystic teratomas are more common in children and adolescents and have no special imaging characteristics, thus, the final diagnosis depends on the pathological examination. ${ }^{[22]}$

Surgical resection is thought to be the best method of relieving compressed symptoms. ${ }^{[15]}$ All of the published cases have undergone laminectomy for the purpose of removing the cyst. However, the residual cyst wall might be associated with recurrence due to adherence of the cyst wall to the cord ${ }^{[23]}$ Hence, only in 4/11 of the published cases, the cyst could be completely resected. ${ }^{[7]}$

The prognosis of our case is comforting. The outcome of our case was that it presented no recurrent signs on MRI examination.

\section{Declaration of patient consent}

The authors certify that they have obtained all appropriate patient consent forms. In the form the patient(s) has/have given his/her/their consent for his/her/their images and other clinical information to be reported in the journal. The patients understand that their names and initials will not be published and due efforts will be made to conceal their identity, but anonymity cannot be guaranteed.

\section{Financial support and sponsorship}

Nil.

\section{Conflicts of interest}

There are no conflicts of interest.

\section{References}

1. Rao GP, Bhaskar G, Reddy PK. Cervical intradural extramedullary bronchogenic cyst. Neurol India 1999;47:79-81.

2. Chaney K, Barclay GP. Entrogenous cysts and congenital diverticula of the alimentary canal with abnormalities of the vertebral column and spinal cord. J Pathol Bacteriol 1959;77:457-71.

3. Baumann CR, Könü D, Glatzel M, Seigel AM. Thoracolumbar intradural extramedullary bronchogenic cyst. Acta Neurochir (Wien) 2005;147:317-9; discussion 319.

4. Zambudio AR, Lanzas JT, Calvo MJ, Fernández PJ, Paricio PP. Nonneoplastic mediastinal cysts. Eur J Cardiothorac Surg 2002;22:712-6.

5. Liu QP, Zhang JN, Zhang L, Han Z, Ma J, Zhou CW, et al. An acute case of paraplegia and spinal bronchogenic cyst. J Orthop Sci 2015;20:923.

6. Fiorelli A, Rambaldi P, Accardo M, Santini M. Malignant transformation of bronchogenic cyst revealed by $99 \mathrm{mTc}-\mathrm{MIBI}-$ SPECT. Asian Cardiovasc Thorac Ann 2012;20:347-9.

7. Ma X, Li W, Niu C, Liang F, Guo L, Shakir TM, et al. Intraspinal bronchogenic cyst: Series of case reports and literature review. J Spinal Cord Med 2017;40:141-6.

8. Yamashita J, Maloney AF, Harris P. Intradural spinal bronchogenic cyst: Case report. J Neurosurg 1973;39:40-5.

9. Agnoli AL, Laun A, Schonmayr R. Enterogenous intraspinal cysts. J Neurosurg 1984;61:834-40.

10. Bocciolini C, Dall'olio D, Cunsolo E, Latini G, Gradoni P, Laudadio P. Cervical bronchogenic cyst: Asymptomatic neck mass in an adult male. Acta Otolaryngol 2006;126:553-6. 
11. Arnold PM, Neff LL, Anderson KK, Reeves AR, Newell KL. Thoracic myelopathy secondary to intradural extramedullary bronchogenic cyst. J Spinal Cord Med 2009;32:595-7.

12. Jain SK, Chopra S, Mathur PP. Thoracic neurenteric cyst in a 60 year old male. Neurol India 2004;52:402-3.

13. Zou MX, Hu JR, Kang YJ, Li J, Lv GH, She XL, et al. Bronchogenic cyst of the conus medullaris with spinal cord tethering: A case report and review of the literature. Int J Clin Exp Pathol 2015;8:3937-42.

14. Wang MY, Levi AD, Green BA. Intradural spinal arachnoid cysts in adults. Surg Neurol 2003;60:49-55; discussion 56.

15. Chongyi S, Meng Y, Dejun Y, Yingjie L, Qingpeng L. Lumbar intradural extramedullary bronchiogenic cyst. Eur Surg Res 2008;40:26-8.

16. Ko KS, Jeun SS, Lee YS, Park CK. Sacral intraspinal bronchogenic cyst: A case report. J Korean Med Sci 2008;23:895-7.

17. Baba H, Furusawa N, Chen Q, Imura S, Tomita K. Anterior decompressive surgery for cervical ossified posterior longitudinal ligament causing myeloradiculopathy. Paraplegia 1995;33:18-24.
18. Wilkinson $\mathrm{N}$, Reid $\mathrm{H}$, Hughes D. Intradural bronchogenic cysts. J Clin Pathol 1992;45:1032-3.

19. Silbergleit R, Brunberg JA, Patel SC, Mehta BA, Aravapalli SR. Imaging of spinal intradural arachnoid cysts: MRI, myelography and CT. Neuroradiology 1998;40:664-8.

20. Karadag D, Karagulle AT, Erden A, Erden I. MR imaging of a ruptured intraspinal dermoid tumour with fat droplets in the central spinal canal. Australas Radiol 2002;46:444-6.

21. Manzo G, De Gennaro A, Cozzolino A, Martinelli E, Manto A. DWI findings in a iatrogenic lumbar epidermoid cyst. A case report. Neuroradiol J 2013;26:469-75.

22. Pandey S, Sharma V, Shinde N, Ghosh A. Spinal intradural extramedullary mature cystic teratoma in an adult: A rare tumor with review of literature. Asian J Neurosurg 2015;10:133-7.

23. Gauden AJ, Khurana VG, Tsui AE, Kaye AH. Intracranial neuroenteric cysts: A concise review including an illustrative patient. J Clin Neurosci 2012;19:352-9. 